\title{
A Pilot Research on the Intention to Engage in Digital Piracy of Movies in Kerala
}

\author{
Devipriya P Leeladharan, Sony Vijayan
}

\begin{abstract}
Digital Piracy is steadily growing issue due to the rapid advancement of technology. The Indian film industry is plagued by this issue for many years. This study strives to understand the intention of people who indulge in digital piracy of movies using the theory of planned behavior. It tries to enhance the model by including other antecedents such as moral judgment and self control. A sample of 70 people was selected and Exploratory Factor Analysis and multiple regression was done. It was determined that attitude and self-efficacy had a highly significant relationship with intention to engage in digital piracy of movies. Also Moral judgment was added to the model of theory of planned behavior and a final conceptual model was created.
\end{abstract}

Keywords:Digital Piracy, Moral Judgment, Self-Efficacy, Subjective norms

\section{INTRODUCTION}

India is the second most populated country in the world with the second largest online market. The advent of digitized products and increase in use of smart phones, tablets, computers etc have also increased the chances of illegal duplication of products such as music, movies and software. India is country where people consider movies to be a part of their life. So, Indian motion picture is one of the largest movie producers in the world. Most states in India have their own movie industry. So, with the production of this large number movies comes the issue of its illegal duplication or piracy. The Indian film industry has been plagued by piracy for so many years.

\section{BACKGROUND INDIAN FILM INDUSTRY AND DIGITAL PIRACY AND CINEMA PIRACY}

\subsection{Indian Film Industry and Malyalam Film Industry}

The Indian film industry releases more than thousand movies worldwide and is one of the largest entertainment sectors in the world. This industry consists of Bollywood and other regional film industries. It generates annual revenue of more than $\$ 2$ billion from theatre releases, TV distribution rights and DVD releases. According to the FICCI-EY report, 'Re-imagining India's M\&E sector' Bollywood comprises of $17 \%$ of the films made in the country, but it annually contributes almost $40 \%$ towards the net box office collections. Approximately $75 \%$ of the films released are accounted by the other 29 Film from other Indian languages but they contribute approximately $50 \%$ to the annual domestic box office collections.

Revised Manuscript Received on April 12, 2019.

Devipriya P Leeladharan,MPhil Scholar, Department of Commerce \& Management, Amrita School of Arts and Sciences, Kochi (Email: devz92@gmail.com)

Sony Vijayan,Research Guide, Department of Commerce \& Management, Amrita School of Arts and Sciences, Kochi
One major regional Industry in the Indian film industry is the Malayalam film industry. It is film industry based out of the southern state of Kerala. It is considered to be the third largest film industry in the south after the Tamil and Telugu film industry. It is known for its content driven cinema. Within the regional space Malayalam films registered a $38 \%$ rise in online transactions the year 2017. According to IMDB report, the top 10 grossing Malayalam films made an average of 31.15 crores in revenue for the year 2018 .

\subsection{Digital Piracy and Piracy in movies}

In today's world, technology has been advancing society and businesses; yet, as it does so, it has also its drawbacks. The increase in speed of internet connection, the increase in high capacity storage, the easy accessibility of peer-peer networks sharing pirated movies on the internet have made it easier for the increasing penetration of piracy in India .Danaher and Smith (2014) in their study done during the shutdown of Megaupload a major peer-peer site noted that consumers tended choose legal channels when the said shutdown took place. Their study was done across countries and it was noted that those countries with more preshutdown usage seemed to have a larger increase in digital sale and rentals of movies than countries with less preshutdown usage. This in turn gave them the conclusion that illegal file sharing displaces digital movie sales

\subsection{Piracy in Indian Film Industry}

Indian film industry is a vulnerable victim of piracy. As per a recent survey, India ranks at No. 4 globally for online movie piracy and various reports show that the industry loses at least $10 \%-30 \%$ of its overall revenue to piracy. Nowadays, films are available for download within 24 hours of their release. Even worse, movies are leaked online even before their official theatrical release. Major source of these files are cam-recordings in cinemas (FICCI, 2018).

In Kerala in 2012, the Kerala police arrested 1010 people involved in the digital piracy of the movie Bachelor Party. This was the first time in the history of India wherein a large scale arrest was recorded against movie pirates. In spite of legal actions against piracy of movies its still rampant in Kerala. In recent years many movies were released in the sites on the day of their theatrical release while others come within a few weeks time.

\section{Research Objectives}

1. To study the antecedents that affects the intention of individuals to engage in digital piracy of movies using Theory of Planned Behavior.

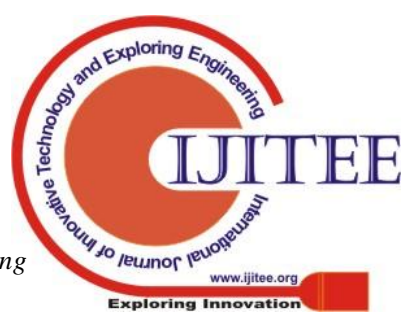




\section{A Pilot Research On The Intention To Engage In Digital Piracy Of Movies In Kerala}

2. To determine whether intention to engage in digital piracy leads to actual behavior

\section{THEORETICAL FRAME WORK, LITERATURE REVIEW AND HYPOTHESES DEVELOPMENT}

Theory of planned behavior is an expansion of theory of reasoned action, which was made to study and understand behavior in various different situations and contexts (Ajzen, 1991). It proposes that a person's intention to perform a behavior leads to his actual behavior. It says that these intentions are influenced by their attitude towards a behavior, subjective norms and perceived behavioural control (Ajzen, 1991). In this study self-efficacy is used to measure perceived behavioral control.

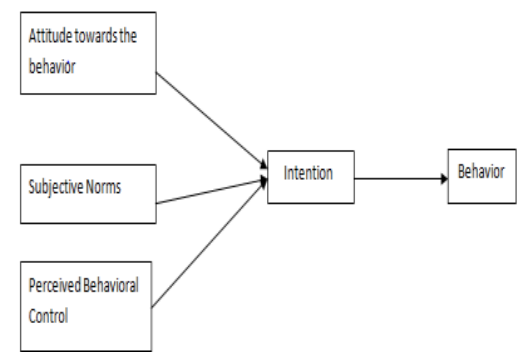

\section{Attitude}

Attitude is one of the major factors in predicting behavioural intentions (Ajzen, 2002: Cronan\& Al-rafee, 2008). Ajzen (1985) define Attitude as "a person's feeling of favorableness or unfavorableness for that behavior". Attitude towards digital piracy is one of the major factors affecting the same. According to a study done by Cronan and Al-Rafee (2008) there was a positive relationship between attitude towards piracy and intention. It was concluded that respondents with higher favorable attitude towards piracy tended to have higher intention towards piracy of digital material.

Hla: Attitude towards piracy positively influences intention to engage in illegal download of movies

\section{Subjective norms}

Subjective Norms is defined as "a person's perceptions of that most people who are important to him think he should or should not perform the behavior in question" (Ajzen, 1985). Social habits seems to have a positive influence on the intention to engage in movie piracy, which in turn means that social factors such as peer pressure affects a person's intention to pirate.(Phau et al, 2013). Males tend to be more exposed to pirating peers who expose them to pirating attitudes in case of software (Higgins, 2006). Significant others didn't believe that the pirating act was wrong and in fact encouraged it (Cronan\& Al-rafee, 2008).

H1b: Subjective norms positively influences intention to engage in illegal download of movies

\section{Perceived behavioral Control (Self-efficacy)}

Perceived behavioral control and intention in case of piracy has a positive relationship which concludes that people with ability and resources to do piracy have a greater chance of pirating digital material (Cronan\& Al-rafee, 2008). It can be measured through self-efficacy.In case of

this study, self -efficacy basically means the consumer's perceived ability to download movies efficiently. Selfefficacy is an appropriate antecedent when we evaluate a person's intention to take on piracy of movies. But in case of the social cognitive theory self- efficacy seems not to have an effect on downloading perhaps because downloading movies requires lesser skill (Jacobs et al, 2012). In other cases self -efficacy has a positive bearing on the intention of an individual to engage in digital piracy of movies (Phau et al, 2013). Krueger and Dickenson (1994) in their research have surmised that there is an increase in perception of opportunity when there is an increase in self efficacy, this leads to a decrease in perception of risk in turn leading to higher risk taking. Thus it can be said that an individual with higher self-efficacy will be involved in the illegal downloading of movies.

H1c: Self-efficacy positively influences intention to engage in illegal download of movies

\section{Self-Control}

In a study Higgins (2006) found that low self-control was directly linked to piracy. It was seen that males tended to have lower self-control than females. In another study it was noted that there was a heightening towards tendency for impulsive and self-gratifying acts when there is an intention to pirate movies. It was seen that individuals with low selfcontrol join others with low self control.In such groups there tend to be favourable attitude towards piracy of movies (Higgins et al , 2007).

H2: Lack of Self-control positively influences intention to engage in illegal download of movies

\section{Moral Judgment}

The current generation seems not be affected by their moral obligations when it comes to the piracy of movies (Jacobs et al,2012). In case of this moral judgment individuals don't feel a great amount of guilt about pirating digital media. They consider it an acceptable behavior. The guilt towards digital piracy is very low. Moral obligation had a large effect on the intention of individuals to pirate digital material. Those who indicated higher guilt towards piracy tended to less of it (Cronan\& Al-rafee, 2008)

H3: Moral judgement negatively influences intention to engage in illegal download of movies

\section{Proposed Conceptual Model}

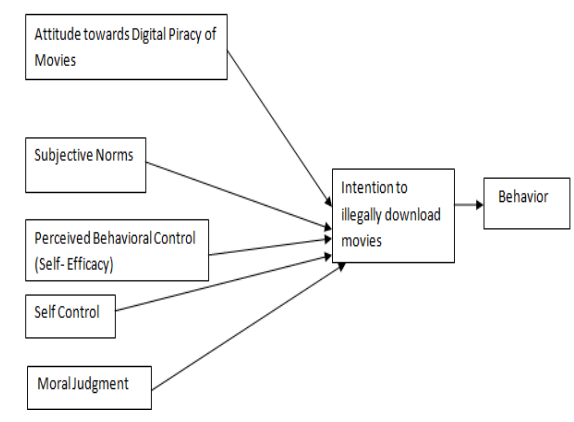




\section{Methodology}

\section{Sample and procedures}

Sample of 70 internet users from Kochi city who did digital piracy who were above the age of 18 years were collected through snow ball sampling. This method was used keeping in mind the sensitivity of the topic and also the difficulty in getting replies from respondents with reference to the illegal nature of digital piracy. The E-questionnaire was administered during a week in April among internet users who were also working (employed). Unlike most studies which involve students as sample population this study focuses on those who are employed. This was a major research gap mentioned by many researchers with regards to digital piracy.

The measures in the study were adopted from Phau et al. (2014) and Jacobs et al (2012). The questionnaire consisted of demographics, 6 statements on Self-efficacy, 3 statements on subjective norm, 4 statements on moral judgment, 5 statements on self control, 4 statement on attitude and 4 statements on intention. A 5-point likert scale was used ranging from 1 (extremely agreeable) to 5 (extremely not agreeable)

\section{Analysis and Results}

A total of 70 reposes were collected and it was analyzed using SPSS 21. The following steps were applied in the analysis of the data:

a. Descriptive Statistics

b. Exploratory Factor Analysis (EFA) and reliability check

c. Multiple Regression

Descriptive statistics was used to understand the profile of the respondents (see Table 1).Out of the 70 respondents $35.7 \%$ were females while $64.3 \%$ were males. $71.5 \%$ were employed full time employed, $21.4 \%$ were self employed and $7.1 \%$ was employed part time. Majority of the respondents ( were in the age group of 23-26 age range followed by $27-30$ age range $(35.7 \%)$ and $31-34$ years age range at $18.6 \% .28 .6 \%$ of the respondents were earning an income between 0-Rs.20000, 48.6\% were earning an income within the range of Rs 20000 -Rs 60000 and the rest 22\% were earning above Rs60000.

Table 1. Profile of Respondents

\begin{tabular}{|l|l|c|c|}
\hline Demographics & \multicolumn{1}{|c|}{ Variable } & Frequency & Percentage \\
\hline \multirow{3}{*}{ Gender } & Female & 25 & 35.7 \\
\cline { 2 - 4 } & Male & 45 & 64.3 \\
\hline \multirow{5}{*}{ Occupation } & Self Employed & 15 & 21.4 \\
\cline { 2 - 4 } & Full time Employed & 50 & 71.5 \\
\cline { 2 - 4 } & Part time employed & 5 & 7.1 \\
\hline \multirow{5}{*}{ Age } & $18-22$ & 2 & 2.9 \\
\cline { 2 - 5 } & $23-26$ & 30 & 42.9 \\
\cline { 2 - 5 } & $27-30$ & 25 & 35.7 \\
\cline { 2 - 5 } & $31-34$ & 13 & 18.6 \\
\hline \multirow{5}{*}{ Incomein (Rs) } & $0-20000$ & 20 & 28.6 \\
\cline { 2 - 5 } & $20000-40000$ & 16 & 22.9 \\
\cline { 2 - 5 } & $40000-60000$ & 18 & 25.7 \\
\cline { 2 - 5 } & $60000-80000$ & 8 & 11.14 \\
\cline { 2 - 5 } & $80000-100000$ & 5 & 7.1 \\
\cline { 2 - 5 } & $>100000$ & 3 & 4.3 \\
\hline
\end{tabular}

EFA was conducted to check the unidimensionality of the factors. 5 factors with Eigen value $>1$ were loaded. Reliability was checked using Cronbach Alpha which was seen to be $>0.7$ ( see Table 2 ). Some statements were seen to be cross loading such statements were removed from further analysis. Finally 5 factor were extracted which were Selfefficacy, Moral Judgment, Self Control, Attitude and Subjective norms. Also Intention being the independent variable was also extracted.

In case of Table 2

Extraction Method: Principal Component Analysis

Rotation Method: Varimax with Kaiser Normalization

Reliability tested using Cronbach Alpha

Notes; $\mathrm{KMO}=0.810$

\section{Multiple Regression}

\section{Findings and Interpretation}

Multiple regressions was used to establish the relationship between intention and other factors extracted. See Table 3 and Table 4.

From the table the following conclusions can be made

Attitude has a highly significant effect on the intention to pirate movies. Thus since the $\mathrm{P}$ Value is less than 0.05 the hypothesis H1a: Attitude towards piracy positively influences intention to engage in illegal download of movies is accepted. A highly favorable attitude towards a behavior ultimately leads to one doing the said behavior. This is true also for digital piracy of movies, if you have a highly favorable attitude towards digital piracy that is heightened chance that you will engage in digital piracy.

Subjective norms tended to have significant effect on intention to illegally download movies. Thus the hypothesis H1b: Subjective norms positively influences intention to engage in illegal download of movies is accepted. This shows that friends, family and colleagues seems to have an influence in an individual's decision to get into digital piracy of movies.

Perceived behavioral control measured in the form of self - efficacy has a highly significant influence on intention to illegally download movies. Thus the hypothesis H1c: Selfefficacy positively influences intention to engage in illegal download of movies is accepted. This results proves various other studies that if you have the capability and materials to do digital piracy ther is a high chance that you will get involved in digital piracy of movies.

Lack of self control has a $\mathrm{p}$ value more than 0.05 indicating that it does not have a significant relationship with intention to illegally download movies. Thus the hypothesis H2: Lack of Self-control positively influences intention to engage in illegal download of movies is rejected. Unlike other studies which concentrated on students and adolescents only this study concentrated on the working class with majority being above the age of 22 years. Thus this finding may be related to the fact that adults have more self-control than students. 


\section{A Pilot Research On The Intention To Engage In Digital Piracy Of Movies In Kerala}

In this case apparently moral judgment has a significant effect on intention to pirate's movies. Since the hypothesis H3: Moral judgment negatively influences intention to engage in illegal download of movies is being accepted

Table 2 Exploratory Factor Analysis

\begin{tabular}{|c|c|c|}
\hline Variables & $\begin{array}{c}\text { Factor } \\
\text { Loadings }\end{array}$ & $\begin{array}{c}\text { Croubach } \\
\text { Alphas }\end{array}$ \\
\hline 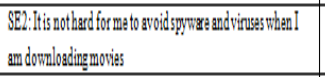 & 829 & \multirow{6}{*}{0.900} \\
\hline 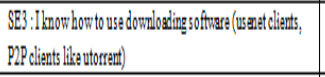 & .725 & \\
\hline SE4 : I can find decantversions of movis I Irant to downlogd & 841 & \\
\hline SES: I can usually can fundthe movisis'mlooling for & .776 & \\
\hline 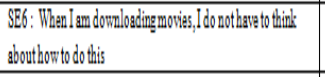 & .780 & \\
\hline SCI: Donzlooding movies has beccoms a habitforms & .627 & \\
\hline 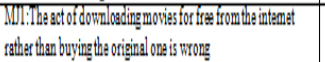 & .723 & \multirow{4}{*}{0.851} \\
\hline 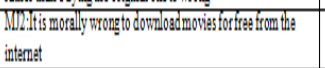 & .789 & \\
\hline 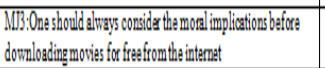 & 854 & \\
\hline 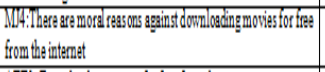 & .870 & \\
\hline 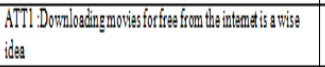 & 883 & \multirow{3}{*}{0.891} \\
\hline 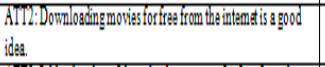 & .928 & \\
\hline 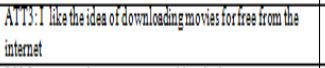 & .803 & \\
\hline 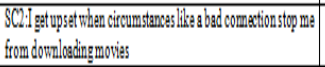 & 849 & \multirow{3}{*}{0.845} \\
\hline 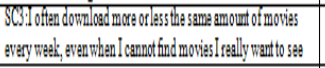 & .774 & \\
\hline $\begin{array}{l}\text { SCS: Sometimes Idornloodmovies rithout actually } \\
\text { consideringit }\end{array}$ & .764 & \\
\hline 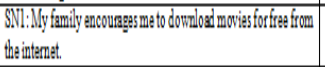 & .798 & \multirow{3}{*}{0.777} \\
\hline 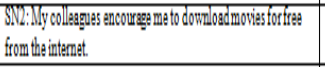 & 841 & \\
\hline 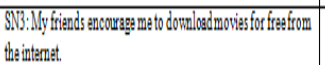 & .767 & \\
\hline
\end{tabular}

Table 3. Multiple Regression

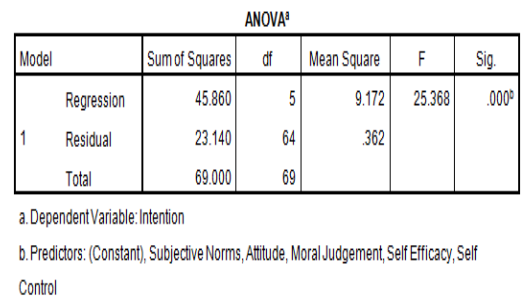

Table 4

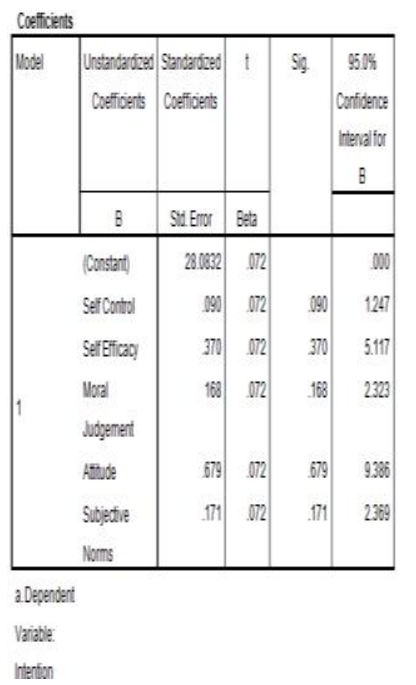

Final Model

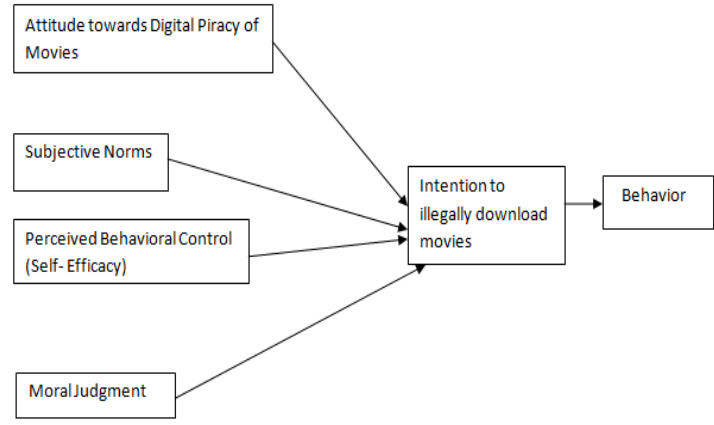

\section{CONCLUSIONS}

The study was conducted due the increasing incidence of digital piracy in Kerala. This study through its model helps to understand why individuals intend to do digital piracy of movies factors like attitude; self-efficacy seems to have a very high significance compared to moral judgment and subjective norms. In this study self control which was one of the variables tended to have no significance towards intention to illegally pirate movies. This study has reinforced the literature already done by many researchers as to the importance of theory of planned behavior in the study of intention to do digital piracy of movies. Moral judgment seems to affect piracy so authorities should make sure to appeal to the morality of people to help decrease piracy of movies. When resources are available people make it a habit to do piracy, so authorities must make sure to make it hard for individuals to access pirated content. Awareness campaigns encouraging different reference groups to appeal to them to stop pirating may also help this situation.

Research gap noted in most studies were that they used sample of students. In this case the sample consisted mainly of people employed in different industries. And such a study has yet to be done in the Indian context. But this being a pilot study the sample taken in very less and the possibility of generalization is low and also a convenience type sampling method was used which also may affect the results. Research gaps include the non inclusion of various marketing environmental factors such as technology, economic means, and knowledge of laws regarding piracy. Also this study only has looked at the intention to engage in digital piracy of movies, other studies may actually directly study the actual behavior towards piracy of movies.

\section{REFERENCES}

1. Ajzen, I. (1985). From Intentions to Behavior: A Theory of Planned Behavior

2. Ajzen, I. (1991). The Theory of Planned Behavior.Organizational Behavior and Human Decision Processes, 50, 179-211.

3. Ajzen, I. (2001). Nature and Operations of Attitudes. Annual Review of Psychology, 52, 7-58.

4. Ajzen 2008

5. Cronan, P. T., \& Al-Rafee, S.(2008). Factors that Influence the Intention to Pirate Software and Media. Journal of Business Ethics, 78(4), 527-545. 
6. Dananher, B. \& Smith, M.D.(2014). Gone in 60 Seconds: The impact of the Megaupload Shutdown on Movie Sales. International Journal of Industrial Organization, 33, 1-8.

7. Gopal, R., Sanders, G. L., Bhattacharjee, S., Agrawal, M., \& Wagner, S. (2004). A Behavioral Model of Digital Music Piracy. Journal of Organizational Computing \& Electronic Commerce, 14, 89-105.

8. Higgins, G. E. (2006). Gender Differences in Software Piracy: The Mediating Roles of Self-Control Theory and Social Learning Theory. Journal of Economic Crime Management, 4(1), 1-24.

9. Higgins, G. E., Fell, B.D. \& Wilson, A.L. (2007). Low SelfControl and Social Learning in Understanding Students' Intentions to Pirate Movies in the United States. Social Science Computer Review, 25(3), 339-357.

10. Jacobs, R. S., Heuvelman, A., Tan, M., and Peters, O.(2012). Digital movie piracy: A perspective on downloading behavior through social cognitive theory. Computers in Human Behavior, 28(3), 958-967.

11. Krueger, N.F,Jr\& Dickson, P. (1994). How Believing in Ourselves Increases Risk Taking: Self-efficacy and Perceptions of Opportunity and Threat. Decision Sciences, 25,385-400.

12. Malin, J. \&Fowers, B.J.(2009). Adolescent Self-Control and Music and Movie Piracy .Computers in Human Behavior, 25(3), 718-722.

13. Phau, I. Lim, A., Liang, J. \&Lwin M. (2014) .Engaging in digital piracy of movies: a theory of planned behaviour approach. Internet Research, 24 (2), 246-266.

14. Taylor, S. A., Ishida, C. \& Wallace, D.W.(2009).Intention to Engage in Digital Piracy: A Conceptual Model and Empirical Test. Journal of Service Research, 11(3), 246-262.

15. Reimagining India's M\&E Sector, FICCI-EY Report 2018 